NBER WORKING PAPER SERIES

\title{
SURVEY EVIDENCE ON DIFFUSION \\ OF INTEREST AMONG \\ INSTITUTIONAL INVESTORS
}

Robert J. Shiller

John Pound

Working Paper No. 1851

NATIONAL BUREAU OF ECONOMIC RESEARCH 1050 Massachusetts Avenue

Cambridge, MA 02138

March 1986

The research reported here is part of the NBER's research program in Financial Markets and Monetary Economics. Any opinions expressed are those of the authors and not those of the National Bureau of Economic Research. 


\section{Survey Evidence on Diffusion of Interest \\ Among Institutional Investors}

\section{ABESIRAECI}

Contagion or epidemic models of financial markets are proposed in which interest in or attention to individual stocks is spread by word of mouth. The models give alternative interpretations of the random walk character of stock prices. A questionnaire survey of institutional investors was undertaken to ascertain the relevance of such models. Questions elicited what fraction of these investors were unsystematic and allowed themselves to be influenced by word-of-mouth communications or other salient stimuli. Fough indications of the infection rate and removal rate were produced. Investors in stocks whose price had recently increased dramatically to a high F/E ratio were contrasted with a control group of investors.

Robert J. Shiller Department of Economics, Cowles Foundation and School of Management Yale University Box 2125 Yale Station New Haven, CT OS520 (203) $436-0685$
John Found Office of the Chief Economist Securities and Exchange Commission Foom 6023, Stop $6-3$ 450 Fifth $5 t$. NW Washington, D. C. 20549 (202) 272-7147 
Survey Evidence on Diffusion of Interest

\section{Among Institutional Investors}

Cantagian madels, like thase used by epidemialogists to study the transmission of disease (e. g., Bailey [1975]) or social psychologists to study rumors or fads le. g., Barthol omew [1982]) would seem to be naturally of relevance to understanding the spread of investor interest in specific financial assets, and hence to understanding the predictability of returns, volatility of prices or volume of trade in financial markets. Psychologists have shown that direct interpersonal communication among peers is of singular importance in the transmission of attitudes (see for example McGuire [1969]). Interpersonal communication among peers seems to produce the kind of attention and reassurance that leads to changes in behavior. This fact is well recognized today in marketing: advertisements often try to create the impression of such communication.

The relevance of such contagion models in finance remains today one of conjecture; there is little concrete evidence concerning them. Fiesearchers perhaps despair of studying them, since they feel that they do not know how to disentangle such behavior from behavior that is purposeful and intelligent. It should be noted, though, that the psychological literature does. not hypothesize that the above models apply only to the less 
intelligent individuals. Our hypothesis here is that the above models apply in important ways to many of those investors, whom we will call "diffusion investors" " who do not use trading rules that cause them to respond systematically to evidence but allow attitudes to diffuce through them by word of mouth. of course, other "systematic investors" may tend to offset somewhat the effect of the diffusion investors on price.

The present study is concerned anly with professional institutional investors, who would seem likely to be more intelligent and knowledgeable than most other investors. The object of our study was to ascertain by survey methods the importance among them of diffusion investors and to inquire into the source, time pattern, and interpersonal extent of their attention to particular stocks. Since diffusion investors may not be equally distributed across stocks, the study distinguishes between a control group of randomly selected stocks and a group of stocks in which diffusion investors were thought possibly concentrated.

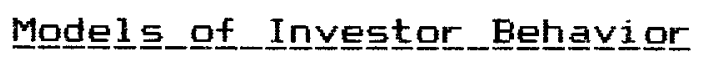

The classic general epidemic model of Kermack and Mckendrick [1927] used to represent the spread of contagious diseases has also been used to represent the time pattern of rumors, attitudes or fads. The model in its simplest form 
hypothesizes that the number $I_{t}$ of infectives for, in our application, interested people) is increased by an amount per unit of time equal to an infection rate $b_{t}$ times the number of infectives, while $b_{t}$ is itself proportional to the number $s_{t}$ of susceptibles. At the same time, infectives cease to carry the disease (in our application, lose interest) and become immune to the disease at a rate per unit of time equal to a constant removal rate $g$ times the number of infectives. The time path of It can show a hump shaped pattern through time, rising at first and then declining, or a decaying form in which the epidenic only declines from its initial intensity.

A number of modifications to this model may seem appropriate for modelling word-of-mouth communications. There may be an additional source of "infection" other than just word-of-mouth communication, Bartholomew [1982]. Something had to start the epidemic, and it may continue to exert influence. The assumption that persons are ultimately immune may be inappropriate, and it may be that persons removed from the infective pool become again susceptibles, Bartholomew [1982]. The constant removal rate assumption may be replaced by the assumption that persons stop spreading after encountering others who have already heard (Daley and Kendall [1965]). The complete mixing assumption that underlies the simple general epidemic model may be replaced by assumptions of a spatial pattern to transmission (Mollison [1972]). 
Common to all these variations on the classic general epidemic model are some notions of an infection rate and removal rate. We can get some rough idea of their values directly from survey data. In this paper, we shall estimate the infection rates and removal rates as constants, and in particular we shall modify the general epidemic model so that the infection rate does not depend on the number of susceptibles. This makes sense in terms of the general epidemic model if the number of infectives remains sufficiently small in our sample that the number of susceptibles is always close to the entire population. The differential equation for the total amount of interest for a particular stock among all people $I_{t}$ is then just:

$$
d I_{t} / d t=(b-g) I_{t}+u_{t}
$$

where $u_{t}$ is due to the "source" of the epidemic.

Supposing that $g<b$ and that the source $u_{t}$ of the epidemic has an influence only for an instant (as would be the case if, for example, the source was a single widely publicized news story at time os then the total interest in the stock would follow an exponential decay pattern. However, hump shaped patterns for total demand for the stock could still be produced by assuming that total demand for the stock is a distributed 1 ag on $I_{t}$ lif investors take time to invest after their initial interest) or if the "source" continues to attract interest for a while, as for example if it too had an exponential decay pattern. 
Other plausible assumptions will produce $I_{t}$ that closely resembles a random walk. Suppose that $g$ is only a little smaller than $b$ and that the "source" is serially uncorrelated noise (formally we may replace $u_{t} d t$ with the stochastic differential of a Wiener process). Such serially uncorrelated $u_{t}$ might come about as attention is drawn to the stock by random associations with other events. Here, the uncorrelated shocks to demand are cumulated by an (ever changing) pool of interested investors, to produce a level of interest whose change is nearly unforecastable. Such an outcome could be part of the reason for the approximate "random walk" behavior of stock prices, though of course the actions of some systematic investors must also play a role in producing such behavior.

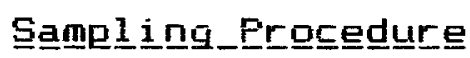

A control group of 10 stocks was selected at randon from the standard and Poor"s Daily stock Price Records for the New York Stock Exchange, American Stock Exchange and Over the Counter Stocks. An "experimental" or "boom" group of 10 stocks was selected from the 1 ist of 25 stocks experiencing highest price increases in the preceding year, as reported on the first page of

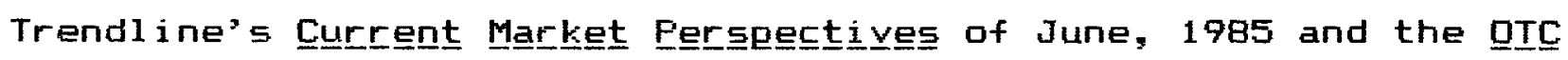
Chagㅡㄹ Mannual of May-June 1985. Each stock in the 1 ist was given a score equal to the average of the standardized values of the 
stock"s price increase over the preceding year, and price/earnings ratio. A news search was done for the stocks, to exclude special events; these were merger and acquisition announcements in which the company was the target. Also excluded were stocks that had had higher split-adjusted price in an earlier year than the maximum achieved in the sample year. From the remaining, the stacks with the top 10 scores were selected. 1

The average (weighted by number of completed questionnaires) E/F ratio in the experimental group in June 1985 was -025, compared with .056 in the control group. The weighted average price increase from the end of June 1984 to the end of June 1985 in the experimental group was $184.5 \%$, compared with $9.0 \%$ in the contral group. ${ }^{2}$ The weighted average turnover rate of shares (all investors, individual as well as institutional) in June 1985 in the experimental group was $8.0 \%$, campared with $4.7 \%$ in the control group. The weighted average change between June 1984 and June 1985 in the consensus forecast of fiscal 1985 earnings as reported on the IBES Earnings Forecast Data Base was

1. The experimental group stocks for which we have completed questionnaires (number in parentheses) weres Barris Industries (1), Chilton Corp (1), Limited, Inc. (11), Marion Labs (3), Mylan Labs (4), Follins Environmental Services (5), Safecard Services (1), U. 5 . Health Care Systems (12), and Zenith Labs (3). The contral group stacks were Continental Illinais Holding Company (2), NCF Corporation (12), Fittston (5), Service Fracturing (1), Stocker and $Y a l e(2)$, and Unitrode (B).

2. E/F ratios and price increase figures exclude Continental Illinois Holding Company. 
$35.6 \%$ in the experimental group and $-25.3 \%$ in the control group. 3

The experimental group was chosen in response to recent studies showing negative abnormal returns for high price increase and high F/E stocks. Dekondt and Thaler [1985] found that stocks whose price had risen very dramatically tended to have negative abnormal returns in subsequent years. A number of other studies have shown that stocks whose price is high relative to earnings tend to have negative abnormal returns. Reinganum [1981] claimed that the effect of the price relative to earnings was really subsumed by a "size effect," however Reinganum"s finding was disputed by Basu [1983] and Peavey and Goodwin [1983]. These studies thus suggest that high price increase and high P/E stocks may be overpriced (perhaps because of a fashion or $f a d$ ) and thus tend to do poorly subsequently.

Dur survey chanced upon a boom in companies related to the movement toward cutting health care costs: there were three generic or consumer drug companies in our experimental group and a manager of health maintenance organizations Labs. athers in the experimental group were diverse: there were a producer of young women's apparel, and a disposer of concentrated industrial

3. These data on earnings forecast changes exclude Barris Industries, Chilton Corporation and Safegaurd Services (these accounting for a total of three respondents) in the experimental group and Continental 111 inois ( 2 respondents) in the control group. Most firms in the experimental group experienced little earnings forecast changes the percentage changes were Limited, Inc., 0.8\%, Mari on Labs, 6.9\%, Mylan Labs, $0.0 \%$, Fol 1 ins, 44.9\%, U. 5. Health $89.0 \%$ and Zenith Labs $10.8 \%$ 
waste. Five of the nine firms on which we had responses had doubled their earnings between 1982 and 1984. Four paid no dividends in 1984.

Institutional stockholders in each of the 20 stocks were randomly selected from those firms who had reported to the Securities and Exchange Commission that they held one of the stocks on either March 31 or June $30,1985 .{ }^{4}$ It was found that a number of institutions were selected twice, as holding more than one of the stocks in our sample. It was considered infeasible to ask participation regarding more than one stock by a single institution. Thus institutions were dropped from the 1 ists of stocks until each institution appeared only once.

Of course, since for our experimental group we selected investors in stocks whose prices have increased a lot, we perhaps also selected for successful investors, since most bought some of the stock before the full price increase. However, since our sample was tased on stockholders of record in March or June, 1985, they also held the stock after the price increase that caused stocks to be singled out for our study. Moreover, $73 \%$ of those in the experimental group (as also $85 \%$ in the control group) reported that they still held shares as of the survey

4. All institutional investment managers exercising discretion over accounts with combined equity assets exceeding $100 \mathrm{mill} 11$ on must report on Form 13f. Equity haldings below 10 , 000 shares and al so below $\$ 200,000$ in market value need not be reported. We accessed this information using Computer Directions Advisors, Inc., SFECTFUM III: 13f Institional Stockholders Survey. 
date.

The survey of the decision makers then followed Dillman*s. [1978] "total design method" fairly closely, and was implemented by Donald Deluca at the Foper Center at Yale University. All letters were sent to senior officers of the institutions asking that the questionnaire be forwarded to the "decision makers" who were responsible for the institution's holding of the stock in question. We emphasized that only actual decision makers should fill out the questionnaire. Fespondents were urged to call us collect if they had any questions (we received about 20 phone (alls).

Great effort was made to keep the response rate high by repeated followups of those who did not respond first. A high response rate is more important to the validity of questionnaire results than is sample in the thousands, since a high response rate diminishes the likelihood of important sample selection bias. Questionnaires were first mailed September 17, 1985 with a letter, self-addressed envelope and printed brochure describing the project. The letter emphasized that the results of the project would serve a useful social purpose, and that results would be made public. It was promised that all respondents would remain anonymous and that they would promptly receive a report giving all 1 of our results. The report would include results broken down by individual stocks, so 1 ong as this did not reveal identities of participants. The report to then was offered as an 
incentive to participate, as well as some assurance that we were not trying to secure private advantage from the information gathered. Dn September 23 a foll owup letter was mailed, reminding them of the questionnaire and reasserting its importance for research on financial markets. On Gctober 9 a third letter was sent out to those who had not yet responded, with a duplicate questionnaire (in case the respondent had lost the first) and another letter (noting the lack of response) and self-addressed envelope. On November 13 a final letter was sent to those who still had not responded, certified mail, with another questionnaire and self-addressed envelope. The timetable and letter format conformed clasely to those that Dillman found yielded high response rates.

Initial1y, 216 questionnaires were sent, 89 to the control group and 127 to the experimental group. There were 74 completed questionnaires, although after we classified three questionnaires (based on margin comments) as out of frame the total was reduced to 71 , 30 in the control group and 41 in the experimental group. We received 54 letters or phone calls that indicated that the respondent was out of frame, 50 that a total of 57 were out of frame. Of these, 24 said that they never held the stock, and 24 said that they did not decide to buy the stock (that the stock was in a custodial account only, or that it was received as a part of a distribution). We believe that some who said they never held the stock actually held it as part of custodial accounts, which they did not check for us. The remainder of the 
57 was accounted for by 6 index funds, 3 institutions that used a rigid formula for their investments, and one options manager whose holdings were due solely to rising options premiums. We received 14 letters declining to fill out the questionnaire, and 1 letter indicating that the decision maker was deceased. The remaining 73 institutions did not respond in any way to our letters.

We thus received cooperative responses from $(71+57) / 216=$ $59 \%$ of those in our sample. We are pleased with this response rate. It is lower than those attained by Dil1man, but our study suffered the handicap that we had to obtain the cooperation of two persons for each questionnaire, and that the questionnaire asked questions that respondents may feel are sensitive.

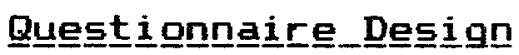

Separate questionnaires were prepared using a word processor for each of the 20 companies in our sample. The name of the company appeared throughout the questionnaire, to affirm clearly our interest in investor behavior with regard to that stock only.

Some of the questions on the questionnaire were aimed at evaluating and calibrating the kinds of models described above, and some were aimed at stimulating the interest of the 
respondents. Their interest was important, as the only incentive offered to participate in the survey was that respondents were promised all the results of the survey. When possible the questions were worded so that the same question could be directed to individual investors if there is a subsequent survey of them.

In each of the questions that follows, the average answers among those answering the question to the question are shown in brackets [] for the control group first, and then the experimental group. In questions in which respondents answer by choosing among items, the numbers in parentheses are the percent among those answering the question who chose that item in the control and experimental groups respectively. Standard errors (in percentage points when what appears above is a percent) appear below, in parentheses 0. Also shown, after n:, are the number answering the question in the two groups.

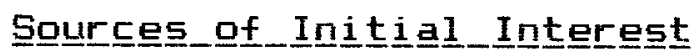

It is important for our purposes to identify to what extent attention was drawn to the stocks by interpersonal communications. Moreover, the identification of the "diffusion investors" is necessary for the estimation of parameters of the 
model above which describes them. 5

Did any of the following motivate your initial interest in a way that led to your purchase _._._____. Corp. stock?

[CIFCLE DNE NUMBER FOR EACH]
YES NO

a. An investment professional.

$$
\begin{array}{cl}
1 & 2 \\
{[53 \%, 75 \%]} & {[47 \%, 25 \%]} \\
(9 \%, 7 \%) & (9 \%, 7 \%)
\end{array}
$$

$n: 30,40$

b. A person who is not an investment professional.

$\begin{array}{cc}1 & 2 \\ {[10 \%, 30 \%]} & {[90 \%, 70 \%]} \\ (5 \%, 7 \%) & (5 \%, 7 \%)\end{array}$

$n: 30,40$

c. A newspaper, magazine, television or radio show.

$\begin{array}{cc}\begin{array}{c}1 \\ {[0 \%, 15 \%]} \\ (-, 6 \%) \\ n: 30,40\end{array} & \begin{array}{c}2 \\ {[100 \%, 85 \%]} \\ (-, 6 \%)\end{array} \\ \text { If YES, name of periodical or show: }\end{array}$

5. This question asks subjects to report on the sources of their own behavior, and thus is of the kind that is widely criticised. However, even critics of such questions will admit that "Accurate reports will occur when influential stimuli are salient and are plausible causes of the responses they produce." (Nisbett and Wilson, 1977.) We think that it is plausible that investors can accurately report what first attracted serious interest in a stock. 
d. An Investment advisory newsletter or brokerage house recommendation.

$$
\begin{array}{cc}
1 & 2 \\
{[30 \%, 52 \%]} & {[70 \%, 48 \%]} \\
(8 \%, 8 \%) & (8 \%, 8 \%)
\end{array}
$$

$n: 30,40$

$$
\begin{array}{r}
\text { If YES, name of newsletter } \\
\text { or brokerage house: }
\end{array}
$$

e. My initial interest was the result of my, or someone elsexs, systematic search over a large number of stocks (using a computerized or other similar search procedure) for a stock with certain characteristics.

$$
\begin{array}{cc}
1 & 2 \\
{[67 \%, 25 \%]} & {[33 \%, 75 \%]} \\
(9 \%, 7 \%) & (9 \%, 7 \%)
\end{array}
$$

$\pi: 30,40$

The wording "motivate your initial interest that 1 ed to your purchase" in the above question was chosen with the idea that it would induce the respondent to think of a discrete event when serious active attention was first shown the stock. They often checked more than one as yes, but it is plausible that more than one of these items were involved in the event. For example, both a and e could be yes if a professional colleague reported a systematic search. A number of respondents circled only yes"s, and left other 1 ines blank. If a respondent checked only yes*s in a multiple-item question like this, the blanks were interpreted as no*s in the percentages reported here.

The most striking contrast between the control and 
experimental groups is in item e. Notably, most of the investors in the experimental group denied that they were systematic in their decision to buy the stock, that is, they answered no to part E. ${ }^{6}$ We regard this result as providing significant support to the general notions in the contagion models described above as applied to stocks in the experimental group. Those answering no to part $e$ will be defined as "diffusion investors" for what fol 1 ows.

The experimental group also showed somewhat more tendency, relative to the control group, to be influenced by other investment professionals, as well as by nonprofessionals, mass media, and investment newsletters.

If the respondents indeed interpreted this question as we intended, we see that interpersonal communications among peers were quite important as a source of interest. For both the experimental group and control groups, the majority asserted that their initial interest was prompted by discussions with other investment professionals. The results are emphatic that initial interest is not generally produced by individuals outside the investment community or by general news media.

of course, these results might also be interpreted as confirming what we might expect of any professionals: they learn

6. Only 2 respondents, or $5 \%$ of the $75 \%$ reported above as answering no had left the line blank, the others actually circled no and thereby asserted that they were unsystematic. 
from each other more than from primary sources. But the fact that they are professionals does not itself necessarily imply that initial interest in individual stocks comes from colleagues. Frofessionals might well interact by discussing broader strategy or exchanging general information, and interest in individual stacks could well be the result of calculations made by individual decision makers. We see that this is not generally the case.

Further evidence on the plausibility of contagion of interest, particularly among the experimental group, can be found in their reported recollections of their expectations, on the date when their shares held reached their maximum, for the percentage increase in their holdings in the succeeding year: an average increase expected of $33 \%$ for the control group and $54 \%$ for the experimental group. We also asked whether the respondent was "sufficiently enthused about your purchase of

Corp. that you thought about it during your leisure hours." of the contral group, $37 \%$ said yes, of the experimental group, $63 \%$ said yes. We did not think it feasible to ask respondents to recall their level of enthusiasm before they purchased, so the difference between groups on this question may be due only to the success of the experimental group. But with such expectations and enthusiasm contagion of interest is certainly plausible. 


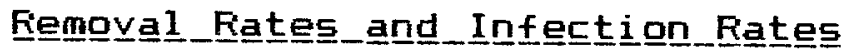

As a preliminary, the following two questions about timing were asked:

As nearly as you can remember, on what date was it that the number of shares you held (in your own portfolio or portfoligs you manage) in _.._._._._. Corp. reached its max i mum?

month

year

$[1984.55,1984.80]$

$$
(.47,-25) \quad n: 29,39
$$

Roughly how long had it been before the DATE WHEN SHARES HELD REACHED MAXIMUM (preceding question) that you were first actively involved (thinking about investing or actually investing) in Corp.?

months

$$
\begin{aligned}
& {[24.3,12.5]} \\
& (7.4,3.2)
\end{aligned} \quad \text { n: } 27.39
$$

We will call the date of the questionnaire minus the answer to the first of these questions $t_{1}$, represented in units of years. and the answer to the second (in years) $t_{Z}$. Then we will define the total time since the individual became interested in the stock as $T=t_{1}+t_{2}=$

To estimate the parameter $g$, the rate of decay of interest, we made use of the following question:

7. The distribution of dates in the answer was quite skewed to the left; most dates were more recent than the average date. 
Approximately what percent of your total time did you spend thinking about, analyzing, and discussing Corp. in a typical weel near the datete when

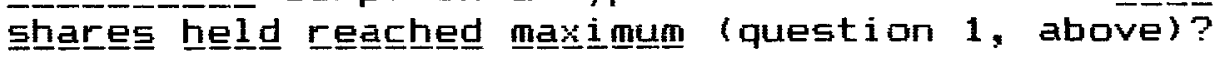

$$
\begin{aligned}
& {[4.5 \%, 9.0 \%]} \\
& (.87,1.7) \quad \text { n: } 28,39
\end{aligned}
$$

In a typical week, approximately what percent of your total time do you curreently spend thinking about, analyzing, and discussing Corp:?

$$
\begin{aligned}
& {[1.5 \%, 2.3 \%]} \\
& (.27, .40) \quad n=28,39
\end{aligned}
$$

Calling the answers to the above questions $y 1$ and $y z$ respectively, for each individual the estimate of $g$ was taken as $g=\ln \left(y_{2} / y_{1}\right) / t_{1}$. The sample average $g$ was computed for diffusion investors who did not round either $y_{1}$ or $y_{2}$ to zero and for whom $t 1$ was at least 4 months. There were 18 such investors. The estimate of average $g$ was 1.42 with a standard error of .35. This estimate of average $g$ implies a half 1 ife $(1 n 2 / 9)$ for interest of .49 years. One survey (McGuire [1969]) on estimates in the psychology literature of removal rates from memory after persuasive communications concluded that the "typical persuasive communication has a half-life of six months" but that different experiments produced widely different half lives. 8 Thus, our estimate of average $g$ is consistent with the notion that the decline of interest is due to the same process of forgetting that has been studied by psychologists.

8. McGuire, "The Nature of Attitudes," pp. 25.3-4. There is also a literature in marketing which produces estimates of half lives. for memory that are not widely different from these. See Bagozzi and Silk [1983]. 
To get an idea of $b$, the infection rate, the following questions were asked:

Roughly how many people have you personally talked to explicitly about Corp. stock?

$$
\begin{aligned}
& {[7.2,21.0]} \\
& (1.4,6.5)
\end{aligned} \quad n=28,41
$$

How many of these people would you guess might have become seriously interested in ______Corp. as a result of your discussion with them?

$$
\begin{aligned}
& {[4.2,10.0]} \\
& (1.2,4.1) \quad n=27,37
\end{aligned}
$$

How many institutional investors in Corp. coutside your own firm, if you are affiliated with an institution) have you spoken to about Corp.?

$$
\begin{aligned}
& {[0.8,2.9]} \\
& (.32, .58) \quad n=29.39
\end{aligned}
$$

We were surprised at how big the answers to the above questions were. If we take the answers to the second question at face value, there is extensive contagion of interest. The answers to the third question suggest, given the relatively small number of institutional investors in the individual stocks, that the set of institutional investors in a particular stock in the experimental group is so interconnected that it might even be regarded as a "small group" as defined by social psychologists. However, $44 \%$ of the respondents in the experimental group answered zero to the third question.

9. Two extreme outlier answers were dropped from the sample. We thought that the question must have been misinterpreted. 
The total interest engendered by the individual is, by the model,

$$
b \int_{0}^{T} I(s) d s=\left(b I_{0} / g\right)\left(1-e^{-g T}\right) .
$$

To convert the total interest engendered to the total number of people who became interested, we may divide the above expression by $I_{o}$. Setting the resulting expression equal to the answer $x$ to the second of the above questions and solving for $b$, we find that $b=x g /\left(1-e^{-g T}\right)$. This estimate of $b$ was computed for each individual and the individual estimates averaged to produce an estimate of average b. For the experimental group the average infection rate was 15.64 , with a standard error of 6.03 , while for the control group the average infection rate was 7.46 with a standard error of 2.23.

The estimated infection rates are so high as to be wildly implausible as inputs to our model. Since it is so much higher than the removal rate, this estimated infection rate would imply a rapidly exploding interest for both experimental groups and control groups. We believe that answers to the second question above on which the estimate of the infection rate is based cannot be taken at face value. It will probably be very difficult to pin down the value of the infection rate with any accuracy; suffice it to say only that our results are consistent with the notion that it may be significantly greater than zero. 
What is certainly suggested by the estimated infection rates, even if they have an upward bias, is that the infection rate is higher for the experimental group than it is for the contral group. 10

\section{Iiming}

An important aspect of our view of contagion of interest is that interest spreads from person to person and does not tend to bunch around dates of news events. To check this, we asked:

When were you most active in discussing Corp. stock with others:

[ENTER DATE IN BOXES]

Month: Year

$\overline{[} \overline{1984} . \overline{16}, \overline{1984}=55]$

$(.30, .56)$

$n: 24,35$

There was little such apparent bunching of dates. For two firms (Zenith Labs and Stocker and Yale) there was one date given twice. For ane firm, Limited Inc., one date was given by three respondents. But there was no other such coincidence of dates. For the experimental group: active discussion came on average 1.6 months (s. e. 1.4) before the date when holdings reached

10. The experimental group was selected in such a way that it contains a large number of successful investors, and if people like to boast this may account for the fact that those in the experimental group talked more to others about their investment. This consideration alone would not suggest that they got more people seriously interested in the stock. 
maximum, for the control group 3.2 months (5. e. 1.7).

\section{Diㅡ드드느토므므}

While there is no proof here, and we should not always take answers at face value, we have seen a number of indications that contagion of interest, along lines described in the simple epidemic models, may be important in describing the behavior of institutional investors.

As noted before, it is likely that contagion of interest does not proceed evenly for all stocks at all times: only certain stacks are "interesting". We selected our "experimental" or "boom" stocks for which we thought such contagion likely to be important. This selection was done on the basis of price. We do not have information that any of the stocks in the experimental group were mispriced, only that behavior was observed that might, given information in psychology, suggest that they might be mispriced.

The differences between the groups sorted as they were using price are striking: those in our experimental or boom group were less likely to be systematic, were more influenced by interpersonal communications, talked more to others, were more enthusiastic and optimistic. These differences are likely of course to be due in part to the arrival of some genuine new 
information that reached some institutional investors, which they then spread. This environment, however, is conducive to the judgmental errors uncovered by psychologists, and that may explain why high F/E stocks experiencing high price increases as a group tend to have negative abnormal returns subsequently.

We think these results are in a way confirming of the idea, already expressed in the literature on anomalous statistical evidence, that notions of market efficiency need to be modified. Yet it is far from our minds that we should reject the notions altogether. Certainly there is some tendency for some "smart money" to move prices in the direction indicated by efficient markets theory. There is already a substantial literature that describes how this might happen, models with both optimizing investors and "noise" investors, "rule of thumb" investors, or the 1 ike. 
References

Bagozzi, Fichard F., and Alvin J. 5ilk, "Recall, Fecognition and the Measurement of Memory for Print Advertisements,"

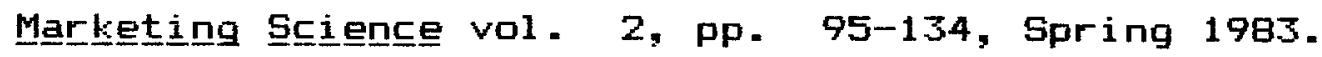

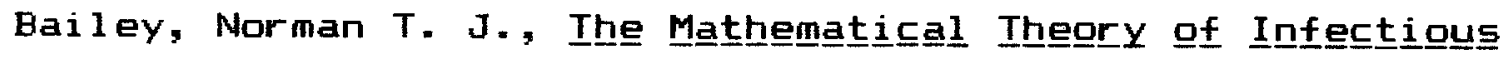
Diㅡㅡㄹㅡㅡㅗ톹, London, Griffin, 1975.

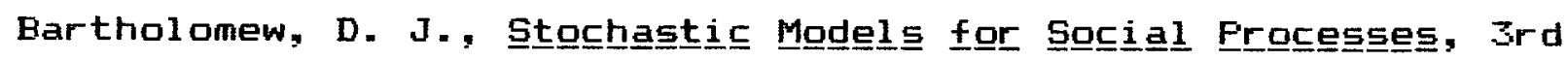
edition, Jahn Wiley \& Sans, Chichester, 1982.

Basu, Sanjoy, "The Relationship between Earnings Yield, Market Value and Return: Further Evidence," Jgourngal of E듬ㅁㅁii도, 12:129-56, June 1983.

Daley, D. J., and D, G, Kendall, "Stochastic Rumors, " Jou the Ingstititute of Mathin. Apel =, 1:42-55, 1965.

DeBondt, Werner F. M., and Richard Thaler, "Does the Stock Market

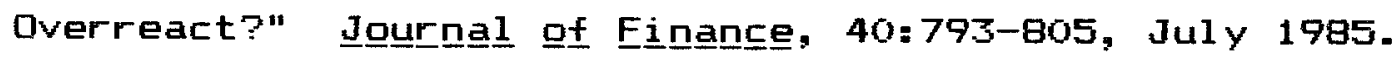

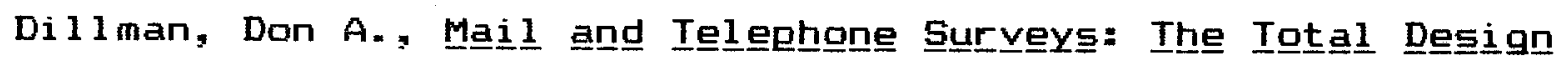
Methog John Wiley and Sons, New York, 1978.

Friend, Irwin and Marshall Blume, The Che

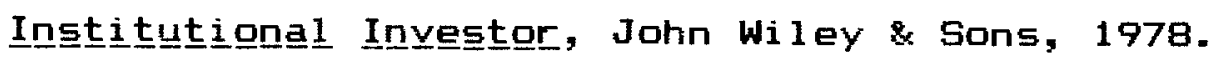

Kermack, W. O., and A. G. Mckendrick, "Contributions to the

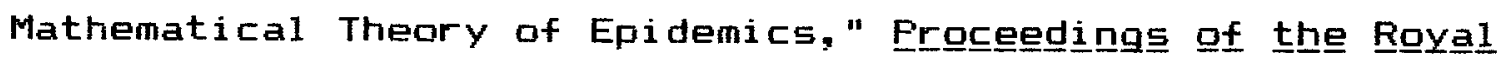




\begin{tabular}{|c|c|c|c|}
\hline Number & Author & Title & Date \\
\hline 1789 & $\begin{array}{l}\text { Charles R. Nelson and } \\
\text { Andrew F. Siegel }\end{array}$ & Long-Term Behavior of Yield Curves & $1 / 86$ \\
\hline 1790 & Martin Feldstein & $\begin{array}{l}\text { U.S. Budget Deficits and the European } \\
\text { Economies: Resolving the Political } \\
\text { Economy Puzzle }\end{array}$ & $1 / 86$ \\
\hline 1791 & $\begin{array}{l}\text { Martin Feldstein and } \\
\text { Gilbert Metcalf }\end{array}$ & $\begin{array}{l}\text { The Effect of Federal Tax Deductibility } \\
\text { in State and Local Taxes and Spending }\end{array}$ & $1 / 86$ \\
\hline 1792 & Martin Feldstein & $\begin{array}{l}\text { Supply Side Economics: 0ld Truths and } \\
\text { New Claims }\end{array}$ & $1 / 86$ \\
\hline 1793 & $\begin{array}{l}\text { Robert J. Barro and } \\
\text { Gary S. Becker }\end{array}$ & $\begin{array}{l}\text { A Reformulation of the Economic Theory } \\
\text { of Fertility }\end{array}$ & $1 / 86$ \\
\hline 1794 & Robert J. Barro & $\begin{array}{l}\text { Reputation in a Model of Monetary Policy } \\
\text { with Incomplete Information }\end{array}$ & $1 / 86$ \\
\hline 1795 & James E. Pesando & $\begin{array}{l}\text { Discontinuities in Pension Benefit } \\
\text { Formulas and the Spot Model of the Labor } \\
\text { Market: Implications for Financial } \\
\text { Economists }\end{array}$ & $1 / 86$ \\
\hline 1796 & $\begin{array}{l}\text { James } M . \text { Poterba and } \\
\text { Julio J. Rotemberg }\end{array}$ & $\begin{array}{l}\text { Money in the Utility Function: An } \\
\text { Empirical Implementation }\end{array}$ & $1 / 86$ \\
\hline 1797 & Stanley Fischer & $\begin{array}{l}\text { 1944, } 1963 \text { and 1985: Modiglianiesque } \\
\text { Macro Models }\end{array}$ & $1 / 86$ \\
\hline 1798 & $\begin{array}{l}\text { Raaj Kumar Sah and } \\
\text { Joseph E. Stiglitz }\end{array}$ & $\begin{array}{l}\text { The Invariance of R\&D to the Number of } \\
\text { Firms in the Industry }\end{array}$ & $1 / 86$ \\
\hline 1799 & $\begin{array}{l}\text { Jacob A. Frenkel and } \\
\text { Assaf Razin }\end{array}$ & $\begin{array}{l}\text { The International Transmission and Effects } \\
\text { of Fiscal Policies }\end{array}$ & $1 / 86$ \\
\hline 1800 & $\begin{array}{l}\text { Warwick McKibbin and } \\
\text { Jeffrey Sachs }\end{array}$ & $\begin{array}{l}\text { Coordination of Monetary and Fiscal } \\
\text { Policies in the OECD }\end{array}$ & $1 / 86$ \\
\hline 1801 & $\begin{array}{l}\text { Joshua Aizenman and } \\
\text { Jacob A. Frenkel }\end{array}$ & Sectorial Wage and the Real Exchange Rate & $1 / 86$ \\
\hline 1802 & Robert W. Fogel & $\begin{array}{l}\text { Nutrition and the Decline in Mortality } \\
\text { Since 1700: Some Additional Preliminary } \\
\text { Findings }\end{array}$ & $1 / 86$ \\
\hline 1803 & $\begin{array}{l}\text { Alan J. Auerbach and } \\
\text { James R. Hines Jr. }\end{array}$ & $\begin{array}{l}\text { Tax Reform, Investment, and the Value of } \\
\text { the Firm }\end{array}$ & $1 / 86$ \\
\hline 4 & Benjamin M. Friedman & $\begin{array}{l}\text { Implications of the U.S. Net Capital } \\
\text { Inflow }\end{array}$ & $1 / 86$ \\
\hline
\end{tabular}


Sogcieㅌy, A115, 700-21. 1927.

Keynes, John Maynard, The General Theory of Employment, Intererest a믐 Mongexy, Harbinger, 1964.

McGuire, William J., "The Nature of Attitudes and Attitude Change," in Gardner Linzey and Elliot Aronson eds., Ihe

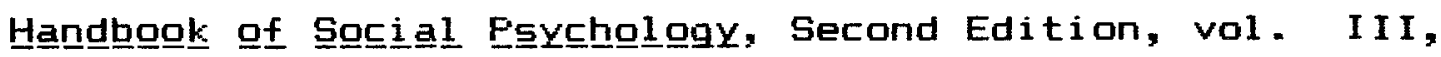
Addison Wesley, Reading Mass, 1969.

Nisbett, Robert E., and Timothy DeCamp Wilson, "Telling More Than We Can Know: Verbal Reports on Mental Processes,"

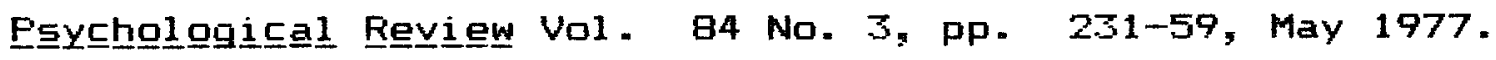

Peavey III, John W., and Dave A. Goodwin, "The Significance of F/E*s for Fortfolio Returns," Journa르 of Fortfㅁlíg Manaagemenent, 9:43-7, Winter 1983.

Reinganum, Marc R., "Misspecification of Capital Asset Pricing: Empirical Anomalies Based on Earnings Yields and Market

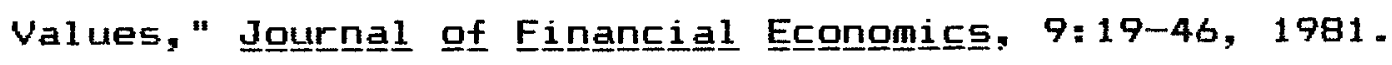

Shiller, Robert J., "Stack Prices and Social Dynamic5," Ergokinggs

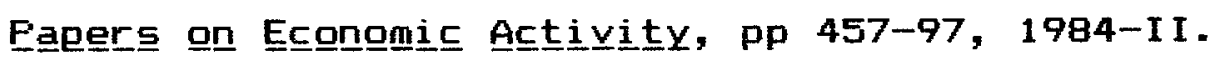

Taylor, Shelley E., and Suzanne C. Thompson, "Stalking the

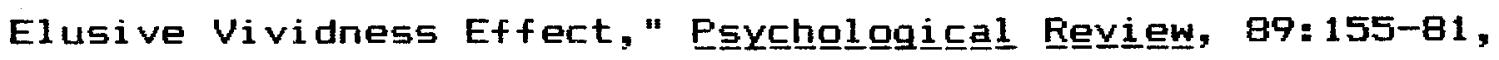
1982. 